\title{
Nuevas notas acerca del cuento árabe del tuerto que se quedó ciego
}

\section{New notes on the Arabic tale of the one-eyed man who became blind}

\author{
DESIRÉE LÓPEZ BERNAL \\ Universidad de Granada, España
}

Resumen: Con base en un breve estudio de Fernando de la Granja, se profundiza en el origen y en los elementos que configuran un cuentecillo árabe protagonizado por un tuerto y que gozó de una notable difusión en las letras árabes premodernas, especialmente en la literatura de $a d a b$, y se incorporó a la tradición literaria española de los siglos XVI y XVII. En este artículo se estudia su génesis en relación con la figura de un destacado personaje de la historia árabe-islámica, Abū Sufyān. A partir de un refrán recogido en distintas obras de la literatura árabe premoderna, y de otros géneros, se establece su posible conexión con el cuento y con la pérdida de la visión de Abū Sufyān. Por último, se identifica su frase final con un hadiz que aparece en numerosas colecciones de tradiciones.

Palabras clave: tuerto; Abū Sufyān; literatura de adab; literatura española; Siglos de Oro.

Recepción: 12 de diciembre de 2015. / Aceptación: 31 de enero de 2020. 
Abstract: Taking a short essay by Fernando de la Granja as a starting point, this article delves into the origins and component parts of an Arabic short story whose protagonist is a one-eyed man. This tale was common in many pre-modern Arabic literary sources, especially in adab works, and was traditionally found in 16th and 17th century Spanish literature. The author of this paper studies its genesis in connection with Abū Sufyān, a prominent character in Arab-Islamic history, and also connects a motif found in various premodern Arabic sources to our tale and Abū Sufyān's complete loss of sight. Finally, a final sentence is identified with a Hadith that appears in several books on traditional themes.

Key Words: one-eyed; Abū Sufyān; adab works; Spanish literature; Spanish Golden Age.

\section{Estado de la cuestión}

El cuentecillo árabe que inspira este artículo llamó la atención del arabista Fernando de la Granja (1970, pp. 387-390), quien se ocupó de él en una de sus diversas publicaciones de las décadas de 1960 y 1970 y puso en relación la cuentística árabe con la española, especialmente la de los siglos dorados.

Subrayando - ante todo- el valor de sus investigaciones y las altas dosis de erudición que emergen de ellas, retomo ahora el hilo de sus aportaciones con el objeto de completar con nuevos datos el conocimiento que hasta el momento teníamos de la génesis y la andadura de dicho cuentecillo por la literatura árabe premoderna. Dado el volumen de la información recabada, se deja para otro momento el estudio de su acogida en la tradición escrita española, desde el siglo Xvi y hasta el xx, con numerosas versiones impresas dentro y fuera de las secciones amenas de la prensa española a partir de mediados del siglo XIX y hasta las tres primeras décadas de la centuria siguiente, que se deben incorporar a los títulos de obras literarias donde su presencia ya fue advertida.

El punto de partida del breve estudio de Fernando de la Granja, al igual que el mío, es un relato muy corto que circuló 
por una serie de libros de bellas letras y paremiología árabes -más adelante preciso desde qué momento-y cuyo exiguo pero chistoso argumento queda resumido en las líneas que siguen: A un tuerto le dan una pedrada o le disparan una flecha que va a parar a su ojo sano, con lo que se queda ciego y exclama: "¡Se nos hizo de noche! ¡El poder pertenece a Dios!”.

El mencionado arabista logró identificar varias versiones de este argumento en la literatura árabe en obras del género del $a d a b$, y otras tantas en las letras españolas entre los siglos XVI y XVIII. Me fijo ahora en la frase con la que concluye el chistecillo y vuelvo igualmente la mirada a los registros más antiguos de su texto en busca de desentrañar la posible atribución del mismo a personajes que representan, en esta literatura de tintes humorísticos y en la tradición oral árabes, el modelo del descuidado. El resultado de las pesquisas descubrirá a otro personaje bien conocido y alejado de dichos modelos en el devenir de la historia.

\section{El tuerto: un personaje tipo del adab al-fukāha ${ }^{1}$}

Durante el periodo premoderno, la literatura árabe de humor tiene en la prosa de $a d a b$ uno de sus mayores y más ricos exponentes. El género constituye un amplísimo catálogo de personajes - con identidad conocida o simplemente anónimos-que encarnan distintos tipos cómicos, los mismos que encontramos en la literatura oral y popular. Son los protagonistas de los relatos de tono más liviano que servían lo mismo como medio de divertimento que como materiales que contribuían a la instrucción del público cultivado de estas obras. ${ }^{2}$ Como es bien sabido, el género desarrolló incluso una vertiente ple-

${ }^{1}$ A lo largo del presente trabajo se utiliza el sistema de transcripción del árabe adoptado por la Escuela de Arabistas Españoles y fijado en la revista al-Andalus.

2 Para conocer más detalles sobre este género de la literatura árabe y acerca de la evolución del término adab desde la época preislámica hasta el siglo Ix, cuando adquiere el sentido con el que se usa en este trabajo, véase Gabrieli, 1986, y Pellat, 1976. 
namente humorística, denominada adab al-fukāha, donde la concentración por capítulo de modelos jocosos es absoluta y sumerge de lleno a quien se adentra en estos libros -o epígrafes de ejemplares del mismo género- en el universo de los parásitos (tufayliyyūn), los avaros (bujalà'), los tontos (hamqà) y descuidados (mugaffalūn o mustajaffūn) o los feos (qibāb), por mencionar sólo a algunos.

El muestrario de personajes tipo que reúne en sus páginas el adab al-fukāba está conformado por aquellos que cargan con cualidades negativas desde el punto de vista del comportamiento y la moral (codiciosos, tacaños, pesados, desvergonzados, gorrones y un largo etcétera), defectos psíquicos (tontos, descuidados o lunáticos) y defectos físicos. Además de los feos, integran este último y diverso grupo personajes que carecen de algunos de sus miembros o poseen alguna imperfección en uno o varios de ellos, como concorvados, mancos, cojos y los que tienen algún tipo de deficiencia en la vista y que, por ese motivo, son el blanco de chistes y bromas o protagonizan situaciones de lo más cómicas.

La pluralidad de estos últimos personajes en la literatura de adab es amplísima y va más allá de los tuertos ( $a l$ - 'ūr), los ciegos (al-'umyān), los bizcos (al-hiūl) o los miopes (al-'umš). Entre ellos, no cabe duda de que los tuertos (al-'ūr) despertaron el interés de los escritores árabes premodernos, y no sólo de aquellos que nutrieron el fértil campo del adab. Al-Ṣafadī (m. 764/1363), autor de una obra biográfica sobre individuos ciegos titulada Nakt al-bimyān fì nukat al-'umyān, en la que también prestaba atención a los tuertos - todos ellos ilustres-, se ocupó de éstos en una monografía que lleva por título al-Š̉ ' $\bar{u} r$ bi l-'̄ur y que constituye la única obra dedicada a quienes se habían quedado con un solo ojo que la tradición escrita árabe premoderna nos brinda. ${ }^{3}$

${ }^{3}$ En esta obra, el quinto de los seis capítulos que sirven de introducción a las biografías de conocidos personajes tuertos versa sobre los refranes y las anécdotas acerca del tuerto verdadero y el que no lo es $\left(f \bar{i} m \bar{a} \hat{y} a^{\prime}\right.$ a min al-amtal wa-l-nawādir fí haqaqi l-a wr wa-gayri $\underline{d} \bar{a} l i k a)$; mientras que el sexto y último reúne poemas sobre la pérdida 
En el plano literario, el prolífico al-Ŷāhị (m. 255/868-869) -conocido precisamente por ser el de los ojos saltones- también se interesó por los tuertos en su Kitäb al-Bursān wa-l- 'urŷān wa-l- 'umyān wa-l-būlān, centrado en los leprosos, los cojos, los ciegos y los bizcos (1990, pp. 566-568).

Al igual que hubo lugares del mundo árabe-islámico medieval cuyos habitantes se hicieron célebres por cualidades como la avaricia (Merv) o la necedad (Hims), ${ }^{4}$ los nombres de otros se vieron vinculados a colectivos, como quienes se hallaban privados de uno de sus ojos. Sabemos por un testimonio que llega a al-Ṣafadī que se decía: "las gentes de Hìt son, la mayoría de ellas, tuertas". ${ }^{5} \mathrm{Su}$ informante contaba la siguiente anécdota acerca de un habitante de dicha ciudad: "Vi a un hombre que tenía los dos ojos sanos y le dije: ‘ ¿Esto es raro!’. Y respondió: 'Mi señor, tengo un hermano ciego que ha cogido su parte y la mía”" (al-Ṣafadī, 1911, pp. 66-67).

Los personajes que habían perdido uno de sus ojos desfilan por los libros de adab lo mismo en capítulos o epígrafes específicos que en otros en los que vienen de la mano de individuos con otra suerte de defecto en la vista. En 'Uyün al-ajbār de Ibn Qutayba (m. 276/889), los acoge un apartado del décimo libro -el Kitāb al-nisā' - dedicado a los ojos (al-'uyūn) (1963, pp. 56-60), donde se cuentan anécdotas como la que sigue: “Dijo al-Așma 'ĩ: 'Una flecha llegó a un hombre tuerto y le alcanzó su

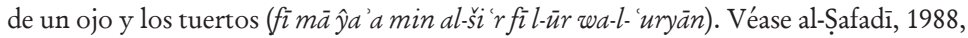
pp. 99-108.

${ }^{4}$ El nombre de Marw/Merv se asocia en la literatura de adab a la codicia de sus gentes, que hombres de letras sobresalientes, como al-Ŷāhiz (s. a., pp. 17-20, 22 y 27; trad. 1984, pp. 88-89, 91-95) o al-Jaṭīb al-Bagdādī (2000, p. 209), se encargaron de subrayar en sus obras consagradas a los personajes avaros y a la avaricia. Si los habitantes de la región de Jurasán eran señalados como los más avarientos, los de Merv se situaban, según estas fuentes, a la cabeza de ellos. Véase también Ibn 'Abd Rabbihi, 1949-1965, p. 174.

${ }^{5}$ Hìt es una población a orillas del Éufrates, en los alrededores de Bagdad. Se le llamó así porque se encuentra en una depresión o barranco de la tierra. Su nombre deriva de la raíz hawwewat-, que significa "bajar por un barranco". Otra explicación de su nombre es que se le habría puesto en honor de su constructor, Hìt b. al-Sabanday/ al-Balanday. Véase Yāqūt, 1977, pp. 420-421. 
ojo sano. Y dijo: ¡Señor, [ahora] yo también iré en el palanquín [maḥmal]!"” (1963, p. 57). ${ }^{6}$

Por su parte, al-Rāgib al-Ișfahānī (m. principios del siglo v/ XI) reservó sendos apartados de sus Mubādarāt al-udabā', uno a continuación de otro, a la pérdida de la vista y las anécdotas de los ciegos sobre su ceguera (nawādir al- 'umyān fì 'amā-bum), y a la pérdida de un ojo (al- 'awar), epígrafe al que sigue uno sobre la condición de bizco (al-harwal) (2009, pp. 342-344).

También en otras obras del género se cuentan anécdotas y chistecillos sobre quienes contemplaban el mundo con un solo ojo. En Natr al-durr, al-Ābì (m. 421-422/1030-1031 o 432/1040) contaba ésta que sigue:

Un tuerto chocó en un mercado con una mujer. Ella se volvió hacia él y dijo: “¡Dios ciegue tu vista!”. Y el tuerto respondió: “¡Señora mía (ya sittî), Dios ya ha cumplido la mitad de tu plegaria!” (2010, vol. 2, p. 211). ${ }^{7}$

El mismo literato recogía otra anécdota en la que un grupo de individuos hablaba sobre la plenitud (kamāl) de los hombres y las mermas ocasionadas en ellos por distintos daños. Uno citaba como medio hombre (en contraposición a la perfección o plenitud mencionada antes) al tuerto, junto con aquel que no supiera nadar bien y quien no estuviera casado. Se dio la circunstancia de que estaba presente un tuerto que no sabía nadar bien ni había contraído nupcias, y que se volvió hacia el que había tomado la palabra y le replicó: “ ¡Si tengo lo que dices, necesito medio hombre para ser nada!" (al-Äbī, 2010, vol. 2, p. 210). ${ }^{8}$

${ }^{6}$ Se repite en otra versión muy próxima en Ibn Abī 'Awn, 1996, p. 192 (núm. 1145). El maḥmal era un palanquín ricamente decorado que se situaba a lomos de un camello y se utilizaba especialmente para llevar a mujeres nobles a La Meca. Al parecer, fue el célebre gobernador omeya de Iraq, al-Haŷȳây b. Yūsuf, el primero en emplear este tipo de palanquines para gloriarse de su prestigio y su autoridad. Véase Buhl y Jomier, 1991. El tuerto del chiste ve en su recién adquirida ceguera la posibilidad de ser transportado como las gentes nobles.

${ }^{7}$ Otra versión del mismo relato la recoge al-Rāgib al-Ișfahānī, 2009, p. 343.

${ }^{8}$ El mismo relato se lee, de nuevo, en al-Rāgib al-Iṣfahānī, 2009, p. 343. 
Atribuir a los tuertos la mitad de las cualidades o asignarles la mitad de algo (como por ejemplo una herencia) por el hecho de faltarles la mitad de la facultad de la vista es uno de los motivos recurrentes en relatos como los anteriores y constituye una de las características que definen a este tipo cómico en el adab al-fukāha (al-Ābì, 2010, vol. 2, p. 211; Ibn Abī 'Awn, 1996, p. 192, núm. 1143). Sobre la figura del tuerto sobrevuela también en esta literatura la sombra del mal augurio, como sucede con el cuervo, al que -como se menciona más adelante- se asoció con él y se le denominó al-a 'wr ("el tuerto"). El relato que sigue ilustra en clave de humor el mal presagio que suponía toparse con uno de estos personajes:

Un rey persa salió a cazar y lo primero que le salió al encuentro fue un tuerto, así que ordenó pegarle y encarcelarlo. Luego se fue y cazó una gran presa. Cuando regresó, hizo venir al tuerto y ordenó que se le diera un don. Y el tuerto dijo: "No necesito tu gracia, pero permíteme hablar". "¡Habla!", concedió el rey. Dijo el tuerto: "Te encontraste conmigo y me pegaste y me encarcelaste, y yo me encontré contigo y cazaste y te mantuviste sano y salvo. Así que, ¿quién es de peor augurio?”. Y el rey se echó a reír y lo dejó (al-Nuwayrī, 2004, p. 142).

En los libros de adab también se ríe de los tuertos por su falta de destreza para realizar actividades como coser o cazar (Ibn 'Āșim, 1987, p. 401, y 2019, p. 460, núm. 1291). Otro de los chistecillos que más debía de ser del gusto de los lectores, por la abundancia de anécdotas en el mismo sentido que encontramos en distintas fuentes, versa sobre juntar a dos tuertos, cada uno de un ojo distinto, para que dieran como resultado un ciego (Ibn 'Āṣim, 1987, p. 205, y 2019, p. 259, núm. 685).

Las causas de la pérdida de un ojo de los personajes tuertos que protagonizan los amenos relatos de la literatura de adab son de lo más variopintas. Algunas situaciones son realmente inverosímiles, como la de aquel hombre a quien una cagarruta de oveja le saltó un ojo (al-Âbī, 2010, vol. 4, pp. 277-278; Ibn 'Āṣim, 1987, pp. 181-182, y 2019, pp. 234-235, núm. 665; Ibn Ḥamdūn, 1996, p. 247, núm. 1095; al-Zamajšarī, 2006, 
p. 254). Los hay que recibieron el impacto de un látigo o una pedrada, ${ }^{9}$ hasta quienes se quedaron a medias luces por el disparo de una flecha en el campo de batalla, tal y como le ocurrió al distinguido tuerto que se esconde tras el anónimo del cuento que centra el presente artículo.

\section{Nuevas notas en torno al cuentecillo en la literatura árabe premoderna}

Las pesquisas de Fernando de la Granja localizaron la versión árabe más antigua del cuento del tuerto que se quedó ciego en el magnífico collar de bellas letras que es al- 'Iqd al-farìd de Ibn 'Abd Rabbihi (m. 328/940), quien brilló como literato al servicio del primer califa omeya de Córdoba, 'Abd al-Rahmān III. Considero oportuno reproducir a continuación su traducción, con el fin de disponer en este mismo trabajo de todas las versiones árabes del relato que se han podido documentar:

Abū Hātim dijo: "A un hombre tuerto le lanzaron una flecha que le alcanzó el ojo sano. Y exclamó: ¡Se nos hizo de noche [anochecimos]! ¡El poder pertenece a Dios!” (1949-1965, p. 443).

Ahora bien, la réplica de este desgraciado personaje mereció que Ibn Abì 'Awn (m. 322/933) - literato oriental contemporáneo del cordobés-incluyera el relato que lo inmortalizaba y su ingeniosa contestación en una colección de respuestas agudas que dejan sin palabras a la que dio el título de Kitāb al-â̂wiba al-muskita. La versión, prácticamente idéntica y que habría que añadir a las recopiladas por Fernando de la Granja, dice así:

Una piedra alcanzó el ojo sano de un hombre tuerto, que se puso la mano en él y dijo: "Se nos hizo de noche [anochecimos]! ¡El poder pertenece a Dios!” (1996, p. 192, núm. 1144).

${ }^{9}$ Al-Ŷāhiz (1990, p. 568) indica que a al-Mujtār b. Abī 'Ubayd (m. 67/687), quien lideró el movimiento a favor de 'Alī b. Abī Tạalib en Kufa, le saltaron el ojo a causa de los latigazos que le propinaron. 
La única diferencia significativa entre los dos textos se encuentra en el objeto que acaba por dejar sin vista al personaje. Uno y otro van a marcar dos tradiciones distintas en el recorrido del cuentecillo por la literatura árabe premoderna, perpetuado en obras del género del adab. Curiosamente, la versión en la que al tuerto le disparan una flecha sólo parece haber sido recogida por escrito por hombres de letras andalusíes, ya que - siglos más tarde de que lo hiciera Ibn 'Abd Rabbihi- el granadino Ibn 'Āṣim (m. 829/1426) tomaba la obra del primero como su principal referente y -entre los cuantiosos materiales que seleccionaba de ella para componer sus Hadā' iq al-azābir - transcribía palabra por palabra el cuentecillo que nos ocupa (1987, p. 156, y 2019, p. 204, núm. 555). Esta versión es la única conservada en la que consta la persona de quien procede la noticia, el tradicionista y transmisor de ajbār Abū Hạtim al-Rāzì (m. 277/890), ${ }^{10}$ quien pudo recogerla -quién sabe- de boca de informantes beduinos. En cualquier caso, hace que debamos remontar la difusión del relato árabe al menos al siglo III/IX en Oriente.

Volviendo al texto que incluyó Ibn 'Abd Rabbihi en su Kitāb al- 'Iqd al-farìd, podría ser resultado de haberse confundido y contaminado hasta fundirse un cuentecillo como el recogido por Ibn Abī 'Awn con aquel otro narrado por este mismo literato (1996, p. 192, núm. 1145) e Ibn Qutayba (1963, p. 57), en el que un tuerto es víctima de un suceso con idéntico desenlace después de que una flecha le acertara en su ojo sano.

A partir de los testimonios escritos conservados, la versión que conoció mayor difusión es la que registraron en sus obras los literatos orientales desde Ibn Abī 'Awn, pasando por al-Rāgib al-Iṣfahānī, quien lo refería en sus Muhạadarāt al$u d a b \bar{a}$ ' en los mismos términos que su homólogo (2009, p. 343), de cuya colección de réplicas ingeniosas tomó claramente este relato.

${ }^{10}$ Se trata de Abū Hātim Muhammad b. Idrīs b. al-Mundir al-Rāzī (n. 195/810811 y m. 277/890), perteneciente a los Banū Tamīm b. Hanzala b. Yarbū y más conocido por su alcurnia, Abū Hātim. Véase al-Ḍahabī, 1996, pp. 247-263, núm. 129. 
Siglos después, Bahā' al-Dīn al-'Āmilī (m. 1030/1621) lo recuperaba para su Kitāb al-kaškūl bajo la forma que sigue:

A un tuerto le dieron una pedrada que le alcanzó el ojo sano. El tuerto se puso la mano en el ojo y dijo: " $¡ S e$ nos hizo de noche [anochecimos]! ¡Alabado sea Dios!” (1385/2006-2007, p. 1050, núm. 3067).

Precisamente, el que se convertiría en proverbial sería -como veremos- el episodio en que un tuerto recibe el impacto de una piedra en el ojo que le quedaba sano.

\section{El tuerto anónimo que se hizo proverbial}

En la literatura paremiológica árabe del periodo premoderno ha sobrevivido un refrán que bien podría estar relacionado con el cuentecillo que nos ocupa y que se cita repetidamente como símil de la prevención. Se aplica a un tuerto, al que se insta a proteger de una pedrada el único ojo por el que todavía puede ver. Reza así: "iTuerto: tu ojo y la piedra!" (a 'wr 'aynu-ka wal-hâyar).

Fue recogido, en primer término, por el célebre filólogo de la escuela gramatical de Basora al-Aṣma 'ì (m. 213 o 216/828 u 831), considerado uno de los tres grandes lexicógrafos y transmisores de la poesía árabe y, por ende, toda una autoridad en la difusión de poesía y ajbār (noticias), que recolectó de labios de los beduinos del desierto durante sus viajes en busca de información sobre asuntos relacionados con la gramática y la lexicografía. Fue uno de sus discípulos, el también filólogo Abū 'Ubayd al-Qāsim b. Sallām (m. 224/838), autor de una recopilación de refranes a la que dio el título de Kitāb al-amtâal, el primero que anotó el proverbio que nos ocupa. Con él daba inicio - bajo la autoridad de al-Așma ì - el "Capítulo sobre guardarse de todo aquel asunto en el que se teme [encontrar] la perdición" (bābal-taḥdìrmin al-amryujäffi-hial- 'atab):11 "Dijo

${ }^{11} \mathrm{El}$ refranero de Abū 'Ubayd sigue un orden temático y no alifático. 
al-Așma 'ĩ: entre sus refranes sobre la prevención se hallan sus palabras: ‘¡Tuerto: tu ojo y la piedra!’” (1980, p. 225, núm. 692). El testimonio de al-Aṣma'ì citado por Abū 'Ubayd al-Q̄àsim b. Sallām desvela que este refrán fue usado por los beduinos del desierto al menos hasta el primer tercio del siglo III/IX, y que fue acuñado debido a que "al tuerto, si le sacan su ojo sano, se queda que no ve, de forma que es más merecedor de ser prevenido que otros" (Abū 'Ubayd, 1980, p. 225). ${ }^{12}$

Por su parte, en el siglo $\mathrm{x}$, el lexicógrafo y hombre de letras de origen persa Abū Hilāl al-'Askarī (m. d. 400/1010) aconsejaba al lector culto de su $\hat{Y}$ amharat al-amtāl, al hilo del mismo refrán, no persistir en aquello que podía conducirle a la perdición, para no acabar como el "tuerto si le sacan su ojo sano y se queda sin vista”. De ahí que instara a quienes se adentraran en su obra a seguir la enseñanza desprendida de aquel breve fragmento de sabiduría y tomar precaución (1988, p. 75, núm. 75). La novedad la ofrecía a continuación, ya que, recurriendo de nuevo a al-Așma'i como fuente, nos informaba que el origen de dicho refrán se encontraría en el siguiente episodio:

Y dijo al-Așma î: el origen de este refrán está en que un cuervo se precipitó sobre la úlcera de una camella y el dueño de ésta no quiso ahuyentarlo, por lo que la camella se agitó. El dueño se negó a quitarlo, y el cuervo hizo sangrar la úlcera. Entonces el dueño de la camella se

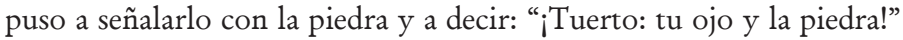
(1988, p. 75, núm. 75). ${ }^{13}$

Y es que, según nos sigue informando Abū Hilāl al- 'Askarī, al cuervo se le llamaba "el tuerto" debido a la afinada vista que se le atribuía, a pesar de ser aves cuyo avistamiento era síntoma de mal agüero en la cultura árabe-islámica: ${ }^{14}$ "Y al cuervo se le

${ }^{12}$ Idéntica explicación es la que proporciona al-Maydānī, 1972, p. 6, núm. 2392.

${ }^{13} \mathrm{La}$ misma información al respecto se recoge en otras obras paremiológicas. Véase al-Maydānī, 1972, p. 6, núm. 2392; al-Zamajšarī, 1987, p. 255, núm. 1081.

${ }^{14}$ Acerca del mal presagio que suponía encontrar a este animal, se crearon numerosos refranes. Cuenta al-Ṣafadī que los árabes acuñaron en primer lugar el refrán "Más de mal agüero que el cuervo de la aparición" (aš' am min gurāb al-bayn), porque si se le aparecía a una familia para buscar alimento y caía en el lugar donde estaban 
llama 'el tuerto' por la agudeza de su vista, así como le llaman al abisinio Abū l-Baydāà [Padre de la blanca], al blanco Abù 1-Ŷawn [Padre del negro] y al mordido "el intacto"” (1988, pp. 75-76). ${ }^{15}$

El poeta ciego Baššār b. Burd (m. 167-168/784-785) se mostraba contrario a dicha denominación, que no hacía justicia a la afinada vista de este pájaro, en un verso en el que satirizaba a un hombre llamado Sayyid ("jefe", "señor") y que dice así:

Cometieron una injusticia cuando lo llamaron Sayyid, al igual que los hombres [al llamar] tuerto al cuervo.

(Baššār b. Burd, 1981, p. 117, núm. 163; al-Ṣafadī, 1988, p. 101).

A juzgar por lo que refieren los literatos árabes, la buena vista del cuervo era tal que incluso era capaz de ver desde debajo de la tierra el mismo alcance o medida que su pico (al-Ṣafadī, 1988, p. 101; al-Yūsī, 1981, p. 185). En otro lugar de la obra citada con anterioridad, Abū Hilāl al- 'Askarī recogía otro refrán que dice: "Más clarividente que un cuervo" (absaru min guräbin), a partir del cual explicaba que este animal cierra siempre uno de los ojos y se limita a mirar con uno solo debido a la agudeza de su vista (1988, p. 195, núm. 313). ${ }^{16}$

La misma aclaración acerca del origen del refrán y el hecho de identificar a la citada ave con el patrón humano del tuerto se lee en al-Mustaqsà fì amtäl al-'arab, el repertorio de refranes de al-Zamajš̉rīi (m. 538/1144) (1987, pp. 255-256, núm. 1081).

sus casas, pedía insistentemente y hurgaba en la basura. Los habitantes de esas casas lo consideraban una mala señal y auguraban mal de ello. Sin embargo — sigue explicando al-Ṣafadī-, más tarde, los árabes rechazaron haberle puesto ese nombre al cuervo por temor al mal agüero y supieron que tenía una vista penetrante y un ojo claro y puro. Entonces dijeron: "Más puro que el ojo del cuervo" (1988, p. 101). En cuanto al cuervo conocido como gurāb al-bayn, se identifica con el moteado o con el que tiene el pico y las patas rojas. Véase Ibn Manzūir, 1981, p. 404.

${ }_{15}$ Al-Maydānī (1972, p. 6, núm. 2392) proporcionaba idéntica explicación al respecto.

${ }^{16}$ Refrán y explicación aparecen también en al-Ṣafadī, 1988, p. 100. De este comportamiento del cuervo también se hacía eco al-Yūsī, 1981, pp. 185-186. 
La asociación del cuervo con el tuerto quedó igualmente reflejada en los diccionarios árabes de la época premoderna, desde el Tahdīib al-luga de Abū Manșūr al-Azharī (m. 370/980) (2004, p. 368), hasta el Lisān al- arab de Ibn Manzūur (m. 711/13111312), quien utilizó el primero como una de sus principales fuentes (1981, p. 3165).

Así pues, el cuervo fue proverbial en el mundo árabe-islámico medieval -al igual que el tuerto- por encarnar la figura de la prevención (al-Zamajšarīi, 1987, p. 255, núm. 1081). En el refrán árabe se apremia al tuerto a prestar atención por igual a su ojo y a la piedra, para proteger al uno de la otra, y así se explicaba de modo expreso en al-Mustaqsà fì amtāl al-'arab: “iTuerto: tu ojo y la piedra! Es decir: “ $i E h$, tuerto, protege tu ojo y guárdate de la piedra!” (al-Zamajšarī, 1987, p. 255, núm. 1081).

En la misma centuria que escribía al-Zamajšarī, pero unas décadas antes, al-Ābi -otro prominente hombre de letras de origen persa- se hacía eco del refrán (2010, vol. 6[1], p. 143, núm. 430). Lo incluía, desprovisto de cualquier explicación, dentro de la amplia colección de proverbios de los árabes (amtāl al- 'arab), a la que dedicó el capítulo cuarto de su enciclopédica obra, en un apartado que reservó para los refranes sobre el alma, el cuerpo, los órganos, las extremidades, el cabello y todo lo que, en definitiva, tuviera que ver con dicha temática (amtäl fíl-nafs wa-l-ŷisd wa-l-a'd $\bar{a}^{\prime}$ wa-l-yawärih wa-l-ša 'r wa-mā yušbibu deālika)..$^{17}$

No podía faltar nuestro refrán, en la misma forma en que se viene citando, en otro de los grandes repertorios paremiológicos de la literatura árabe premoderna, quizá el de mayor difusión y popularidad, el Mâyma' al-amtāal de al-Maydānī (m. 518/1124) (1972, p. 6, núm. 2392).

Asimismo, entre la amalgama de materiales diversos que conforman las entradas de los diccionarios árabes premoder-

${ }^{17}$ En términos cuantitativos, este refranero culto, con 2333 proverbios, supera con creces al refranero del pueblo que al-Ābī recoge en el capítulo 12 de su Natr al-durr y que comprende una más modesta cifra de 352 refranes en árabe dialectal. 
nos, localicé el mismo refrán en la correspondiente a la palabra a wr. Ibn Manzūur indicaba, además, que en el siglo VII-VIII/ XIII-XIV desde el que escribía se trataba de uno de los refranes corrientes de los árabes ( $m i n$ amtāl al- 'arabal-sā'ira), de lo que se infiere que fluía de forma habitual y que seguía haciéndolo en ese momento (1981, p. 3166). Su último rastro en una obra lexicográfica antes de alcanzar la Modernidad se halla en el Tầy al-' arūs de al-Zabīdī (m. 1205/1791) (1974, p. 168). Entre uno y otro, en la segunda mitad del siglo IX/Xv, el egipcio al-Suyūtị (m. 911/1505) también aludía a él en un comentario a su propia recopilación de tradiciones del Profeta titulada $\hat{Y}$ am 'al$\hat{y} a w a \overline{m i} i^{`}(1998$, p. 18), de nuevo a propósito de la prevención (al-tab di $\bar{\imath} r)$.

En la actualidad, se advierten restos del primitivo refrán en otro que mantiene vivo la tradición oral en la zona de Adén (Yemen) bajo la forma: "Si entras en el país de los tuertos... ¡Tuerto, tu ojo!” (id̄ā dajalta bilād al- 'ür... a 'wr 'aynu-ka) (https: // adenblog.com, cuarta parte, refrán núm. 16). En él se advierte que conserva el sentido de prevención que tenía antaño y con el que se difundió en la tradición escrita árabe premoderna.

\section{Abū Sufyān: el tuerto del cuentecillo}

Lo cierto es que el tuerto al que se exhorta en el refrán a proteger su ojo sano podría ser cualquiera. Sin embargo, y teniendo en cuenta la difusión del cuentecillo que nos ocupa, es probable que quien escuchara o leyera el también difundido proverbio recordara el divertido acontecimiento que se narraba en nuestro relato. El reputado filólogo oriental Abū Hilāl al-'Askarī no pudo evitar dicha asociación entre sus comentarios al hilo del mencionado refrán. Sus palabras tienen un valor añadido, ya que se hacía eco de otra versión diferente del cuentecillo. Una reelaboración que nos sitúa en el que podría ser su origen y que dice así: 
Y se cuenta que Abū Sufyān b. Harb perdió uno de sus ojos. Luego una piedra le alcanzó el otro y dijo: " ¡Se nos hizo de noche [anochecimos] y el poder pertenece a Dios!” (1988, p. 75).

La atribución de la anécdota a Abū Sufyān (m. 32/653) no es gratuita. El que fuera acaudalado comerciante de La Meca y jefe del clan de 'Abd Šams, de la tribu de Qurayš, y que tan vigorosamente se opuso a la nueva fe que predicaba Mahoma, perdió uno de los ojos durante el asedio de la ciudad de al-Tâà if, ya del lado musulmán, después de abrazar el islam la noche anterior a la entrada de Mahoma y sus Compañeros y Seguidores en La Meca (Ibn al-Atīir, 1994, vol. 3, p. 9). Lo narrado en el cuentecillo resumiría de forma chistosa un hecho verídico si nos atenemos a lo que refieren fuentes árabes de distinta naturaleza, que se repasan a continuación. ${ }^{18}$

Entre los literatos que primero aluden a la condición de tuerto de este distinguido personaje se cuenta al-Ŷāhiz, que abría con él el capítulo que dedicaba a los tuertos (al-' 'ur $r$ ) en su Kitāb al-Bursān wa-l- 'urŷān wa-l- 'umyān wa-l-ḅūlān (1990, p. 566), citado con anterioridad. ${ }^{19}$ Contemporáneo del prolífico literato de Basora fue Ibn Habīb (m. 245/860), filólogo de la escuela de Bagdad, quien situaba a Abū Sufyān entre los tuertos ilustres que relacionaba en uno de los capítulos de al-Mubabbar (199?, p. 302). ${ }^{20}$

${ }^{18}$ Por alguna de estas fuentes conocemos, además, que el abuelo paterno de Abū Sufyān, Umayya b. 'Abd Šams, también fue tuerto y acabó, como le ocurriría a su nieto, quedándose ciego. Véase al-Ṣafadī, 1988, p. 248, núm. 85; Ibn Hạīib, 199?, p. 296.

${ }^{19}$ El literato de Basora también situaba en al-Ṭa ${ }^{-}$if la pérdida de este primer ojo que hizo que Abū Sufyān quedara tuerto. Previamente, lo había mencionado en la nómina de ilustres personajes que se habían quedado ciegos hasta el momento en que escribía, y que reproduce en el capítulo anterior tomando como fuente una obra homónima a la suya salida de la pluma de al-Haytam b. 'Adī (m. 206-207 o 209/821-822 u 824) (al-Ŷāhiz, 1990, p. 565). Esta última obra, como muchas del intelectual de Kufa, no se ha conservado.

${ }^{20}$ Abū Sufyān es el primero de los nombres que mencionaba. Lo cita también antes, concretamente en el capítulo que reserva a personalidades que perdieron la vista (Ibn Habīb, 199?, p. 296), donde indica que había sido tuerto. 
Tampoco falta alusión al acontecimiento en las obras biográficas sobre los personajes que estuvieron en el círculo de Compañeros y Seguidores de Mahoma. Los historiadores Ibn al-Ațīr (m. 630/1233) (1994, vol. 2, p. 485) e Ibn Haŷar al'Asqaāanī (m. 852/1449), este último también tradicionista y juez egipcio (1995, pp. 237 y 334), informaban que, efectivamente, Abū Sufyān habría perdido el primero de los ojos en el transcurso de la batalla de al-Tá 'if debido al disparo de un hombre de sus propias filas, Sa 'ìd b. 'Ubayd/' Abd Allāh al-Taqafī:

Al-Zubayr transmitió por medio de Sa 'īd b. 'Ubayd al-Taqaâi, que dijo: Disparé a Abū Sufyān la Jornada de al-Tầ' if y le alcancé en el ojo. Entonces se llegó al Profeta, ¡Dios le bendiga y salve!, y dijo: "Este ojo mío ha sido alcanzado por la causa de Dios". El Profeta dijo: "Si quieres, rogaré y te será devuelto, y si quieres [se le concederá] el Paraíso". Y Abū Sufyān respondió: "El Paraíso" (Ibn Haŷar al-'Asqalānī, 1995, p. 334).

En el contexto del campo de batalla, es más fácil suponer que el disparo recibido procedería de una flecha, lo cual conectaría el relato con la versión andalusí que narraban Ibn 'Abd Rabbihi e Ibn 'Āṣim, y explicaría, de esta manera, la presencia en él de la flecha que dejó sin ojo al tuerto protagonista.

Por Ibn Qutayba y otros autores (al-Ŷăhiz, 1990, p. 565) sabemos que - tal y como quedó recogido en el relato que citaba Abū Hilāl al-'Askarī en su Ŷambarat al-amtāl-, una vez tuerto, Abū Sufyān perdió el ojo que le quedaba. Sucedió durante la célebre batalla de Yarmūk, que enfrentó a las tropas musulmanas del califa 'Umar b. al-Jațāàb con el ejército bizantino en el año 24/636, en la orilla izquierda del río Jordán (Bosworth y Kaegi, 2002): ${ }^{21}$

${ }^{21}$ Entre los destacados personajes que perdieron uno de sus ojos en esta contienda se cuentan Mālik b. al-Hārit al-Aštar al-Naja $\overline{1}$, guerrero y agitador político y partidario de 'Alī; al-Aš at b. Qays (m. 40/661), jefe de Kinda; o al-Mugīra b. Šu ba (48-51/668-671), Compañero de Mahoma que estuvo al servicio de los califas bien guiados y de los primeros omeyas. Véase, respectivamente, al-Șafadī, 1988, pp. 199-200, núm. 56; p. 116, núm. 8, y pp. 217-220, núm. 69; e Ibn Habīb, 199?, pp. 302-303. Según 
perdió el ojo junto al Profeta, ¡Dios le bendiga y salve!, en una algarada. Luego sobrevivió hasta el califato de 'Uțmān, ¡Dios esté satisfecho de él!, y se quedó ciego antes de morir. [...] Y se dice que uno de sus ojos lo perdió en la Jornada de al-Ṭā' if y otro en la Jornada de Yarmūk (Ibn Qutayba, 1981, p. 344).22

Conocemos también que, una vez ciego, Abū Sufyān usaba como lazarillo a un esclavo joven (gulām) o cliente suyo (mawlà) para mostrarle el camino: "Al-Baqawī transmitió en una cadena de transmisión (isnād) auténtica de Anas [b. Mālik] que Abū Sufyān entró ante 'Uțmān después de quedarse ciego y un esclavo joven suyo le guiaba” (Ibn Haŷar al-'Asqalānī, 1995, p. 334). En otra fuente se dice: "Y cuando Abū Sufyān se quedó ciego, lo solía guiar un cliente suyo” (Ibn al-Atīir, 1994, vol. 3, p. 9).

En la misma línea que los testimonios anteriores se pronunciaba el autor egipcio al-Halabì (m. 1044/1635) en su biografía de Mahoma titulada Insān al- 'uyūn, donde escribió lo siguiente a propósito de la batalla de al-Ṭà if:

Y entre quienes fueron heridos se encuentra Abū Sufyān b. Harb, al que le alcanzaron el ojo. Y llegó al Profeta, ¡Dios le bendiga y salve!, llevando su ojo en la mano y le dijo: "¡Oh, Enviado de Dios, este ojo mío ha sido alcanzado por la causa de Dios!”. Y el Profeta contestó: "Si quieres, rogaré y te será devuelto, y si quieres [se le concederá] el Paraíso". Y hay una expresión [que dice]: "Un ojo en el Paraíso". Abū Sufyān respondió: "El Paraíso". Y arrojó el ojo de su mano. Su segundo ojo se lo arrancaron durante el combate de la Jornada de Yarmūk, en el momento de luchar contra los bizantinos (2006, p. 164).

Tuerto primero y ciego después, el nombre de Abū Sufyān y su biografía se encuentran también en los repertorios biográ-

este último, al-Mugīra habría quedado tuerto durante la Jornada de Hudaybiyya, a pesar de que tal día no hubo combate entre Mahoma y sus seguidores y los mecanos. Véase Watt, 1986.

${ }^{22}$ Abū Sufyān encabeza la lista de tuertos que Ibn Qutayba inserta en la misma obra (1981, p. 586; la enumeración completa en pp. 586-587). Unas páginas después (p. 588), cita también su nombre entre los ciegos (al-makāfiff). 
ficos dedicados a uno y otro colectivo por parte de al-Ṣafadī en el siglo VII/XIv. La explicación a la pérdida de sus dos ojos la exponía brevemente en al-šu 'ür bi l-'ūr en los siguientes términos:

Fue testigo de al-Ṭà if con el Enviado de Dios, ¡Dios le bendiga y salve!, y le dispararon esa Jornada y le alcanzaron el ojo. El otro ojo se lo alcanzaron la Jornada de Yarmūk, bajo la bandera de su hijo Mu'āwiya (1988, p. 146, núm. 29).

Esta escueta información -como el autor indicaba- es ampliada en la biografía más detallada del personaje que incluía en su Nakt al-bimyān, donde se hacía eco de un relato similar al que recogían las obras de tipo biográfico sobre Mahoma y sus Compañeros que dice:

Y cuando fue testigo de al-Ṭāa if con el Enviado de Dios, ¡Dios le bendiga y salve!, le dispararon esa Jornada y perdió el ojo. Y el Enviado de Dios, ¡Dios le bendiga y salve!, le dijo, llevando [Abū Sufyān] el ojo en la mano: “¿Qué prefieres: un ojo en el Paraíso o que ruegue a Dios por ti que te lo devuelva?”. Respondió: “Un ojo en el Paraíso”. Y lo arrojó. Su otro ojo se lo alcanzaron la Jornada de Yarmūk, bajo la bandera de su hijo Yazīd, y se quedó ciego (1911, p. 173).

Como se puede apreciar, el relato de la pérdida de su segundo ojo por parte de Abū Sufyān y la única versión del cuentecillo del tuerto que se quedó ciego que protagoniza expresamente este ilustre personaje tomaron caminos disociados en las fuentes árabes. Mientras el segundo recrea la respuesta inmediata de Abū Sufyān al recibir el impacto que le hizo quedarse sin visión, los testimonios de biógrafos e historiadores refieren los momentos posteriores y cómo acudió, ojo en mano, a Mahoma. Desconocemos si la atribución a Abū Sufyān del chistecillo del tuerto que se viene tratando fue anterior o posterior a su gestación primigenia y si fue algo puntual o, por el contrario, pudo gozar de una difusión más amplia, a pesar de que sólo nos ha llegado su registro escrito en una única fuente, por lo demás, no demasiado tardía. Con todo, en las fuentes más antiguas en 
que podemos leer el cuentecillo, éste es protagonizado por un tuerto cualquiera.

\section{Un hadiz para servir al bumor}

Es el momento de prestar atención a la frase que cierra el relato árabe. Ya hemos visto que se pone tanto en boca del tuerto anónimo que lo protagoniza en la mayoría de las versiones literarias, como en la de Abū Sufyān en la versión que transmitía Abū Hilāl al-'Askarī en su colección de proverbios a partir del refrán. "¡Se nos hizo de noche! ¡El poder pertenece a Dios!" (amsaynā wa-amsà al-mulku li l-Lāhi) es la ingeniosa exclamación que el desdichado tuerto pronuncia ante la desgracia que acaba de sobrevenirle al perder totalmente la vista a causa de la piedra o la flecha que le ha saltado su ojo sano. Esta exclamación final es la que absorbe toda la gracia del chistecillo y que queda latente en la memoria de quien lo lee o escucha. No se debe, sin embargo, a la ocurrencia ni del tuerto desconocido ni de Abū Sufyān, aunque en el cuentecillo sea mérito de ambos traerla a colación en la situación precisa que se ha descrito.

Se trata de un hadiz pronunciado por Mahoma, transmitido en múltiples colecciones de tradiciones con la garantía de ser sabīh o auténtico. Dice así:

[Transmitido] de 'Abd Allāh b. Mas'ūd, ¡Dios esté satisfecho de él!: Dijo: "El Profeta, ¡Dios le bendiga y salve!, solía decir cuando anochecía: ‘Se nos hizo de noche! ¡El poder pertenece a Dios! ¡Alabado sea Dios! ¡No hay más dios que Dios, Él solo, no tiene un asociado! El poder el suyo y suya es la loa. Tiene poder sobre cada cosa [...]'” (Abū Dāwūd, 2009, p. 406, núm. 5071; al-Bayhaqī, 2009, pp. 84-85, núm. 24; Muslim, 1427/2006, pp. 1250-1251, núm. 2723; al-Nisā'ì 2001, p. 15, núm. 9767 y p. 213, núm. 10333; al-Tirmidīi, 1996, p. 398, núm. 3390). ${ }^{23}$

${ }^{23}$ Las citadas son sólo algunas de las múltiples colecciones de tradiciones donde se encuentra registrado dicho hadiz. 
El mismo transmisor, uno de los más conocidos Compañeros del Profeta, añadía que éste recurría a la misma fórmula cuando amanecía, adaptada a ese otro momento: "¡Se nos hizo de día! ¡El poder pertenece a Dios!” (așbahnnà wa-aşbaha al-mulku li l-Lābi) (Abū Dāwūd, 2009, p. 406, núm. 5071; alBayhaqī, 2009, pp. 84-85, núm. 24; Muslim, 1427/2006, pp. 1250-1251, núm. 2723; al-Nisā'ì, 2001, p. 15, núm. 9767 y p. 213, núm. 10333; al-Tirmidīi, 1996, p. 398, núm. 3390).

La réplica del tuerto del cuentecillo ante lo que le ha sucedido, pese a no ser de su autoría, no está exenta de ingenio. Su gracia reside en que se emplea un dicho de Mahoma sacado de contexto, pero aplicado a una situación igual a la que llevó al Profeta a pronunciarlo, pues también al protagonista de la fortuita situación, de modo figurado, se le hizo de noche y lo alcanzó la oscuridad. El hadiz pierde de este modo parte de su carácter religioso al insertarse en un contexto totalmente profano y ajeno a la religión. ${ }^{24}$ Con todo, al protagonista del relato le sirve perfectamente para proclamar, según la fe islámica, el poder supremo y absoluto de Dios para decretar todo lo que ha de suceder en la vida de una persona.

\section{Conclusiones}

Desligado -salvo en una versión- del nombre de Abū Sufyān, no cabe duda de que el cuentecillo del tuerto que se quedó ciego adquirió la categoría de tradicional al menos en las letras árabes de los siglos IV-V/X-XI, y fue recuperado a posteriori por otros escritores de $a d a b$, lo mismo en Oriente que en al-Andalus, hasta los siglos X-XI/XVI-XVII. Como ocurre con otros cuentecillos, su paso por la literatura andalusí fue clave para su ulterior transferencia a las letras de la España áurea.

${ }^{24}$ Esta práctica es constante en los relatos y las anécdotas que componen los libros de adab, donde hadices, al igual que aleyas del Corán, se convierten en recursos para hacer saltar la chispa de la risa. Al respecto, véase López Bernal, 2018; Malti-Douglas, 1997; Marzolph, 2000, y Tamer, 2009, pp. 24-28. 
A partir de los textos que conservamos, sabemos que la versión que tiene como protagonista a Abū Sufyān y la más difundida, protagonizada por un tuerto anónimo, convivieron al menos durante el siglo IV/X, en que la segunda - vestida de un aire más popular tras la pérdida de la identidad por parte de su infeliz héroe- le fue ganando terreno a la primera hasta imponerse en la tradición escrita.

Respecto a su tradicionalidad, cabría esperar lo mismo que señalaba antes en cuanto a la literatura escrita - aunque sea imposible aseverarlo- en lo referente a la tradición oral oriental de las mencionadas centurias, donde el refrán al que se ha aludido a lo largo del estudio —de uso común al menos hasta los siglos VII-VIII/XIII-XIV en que escribía Ibn Manẓūr- habría contribuido fuertemente a la transmisión del cuento ligado a él en tanto símil para instar a la prevención. La asociación entre el refrán y el cuentecillo se produjo y debió de haber sido frecuente, a pesar de que sólo contamos con una muestra de Abū Hilāl al-'Askarī, que los puso en relación desde época más o menos temprana.

En cuanto al hadiz que remata el chistecillo, sólo se asocia con Abū Sufyān y el episodio de su pérdida de la visión en la versión del relato de la que se hacía eco Abū Hilāl al-'Askarī, que es también la única que vincula este último con quien fuera jefe del clan de 'Abd Šams, sin que sea posible establecer a partir de la documentación que poseemos si, en su origen, el relato nació ligado a tan distinguido personaje de la historia árabeislámica (aunque no hayamos conservado registros escritos anteriores) o fue una atribución posterior.

Por último, conviene destacar que la jugosa presencia y variedad de relatos protagonizados por tuertos y otros personajes con mermas en la vista en la literatura de adab-de la que tan sólo se han ofrecido unas pocas pinceladas al comienzo de este trabajo- los convierte en uno de los modelos cómicos que constituyen su variedad plenamente humorística. 


\section{Referencias}

ĀBī, A. S. M. al- (2010). Natrr al-durr نثر الدرّ (Vols. 2, 4 y 6) (Ed. M.

'A. Qarna). El Cairo: Dār al-Kutub wa-l-Watā̄ 'iq al-Qawmiyya. Aвū DĀWūD, S. b. al-A. (2009). Sunan Abì Dāwūd سنن أبي داود (Vol. 7 ) (Ed. Š. al-Arna'ūt et al). Beirut: Dār al-Risāla al-' Ālamiyya.

АвŪ 'Ubayd, al-Q. b. S. (1980). Kitāb al-Amțāl كتاب الأمثال (Ed. 'A. al-M. al-Qatāmiš). Damasco: Dār al-Ma' mūn li 1-Turāt.

'Āmilī, B. al-D. al- (1385/2006-2007). Al-Kaškūl الكشكول (Vol. 3) (Ed.

Al-S. M. al-S. H. al-Mu 'allim). Qum: al-Maktaba al-Haydariyya. 'AsKARİ, A. H. al- (1988). Ŷambarat al-amtāll جمهرة الأمثال (Vol. 1) (Ed.

A. 'Abd al-Salām). Beirut: Dār al-Kutub al-'Ilmiyya.

Azharí, A. M. al- (2004). Tahdî̉b al-luga تهذيب اللغة (Vol. 2) (Ed. A. 'A. al-R. Mujaymar). Beirut: Dār al-Kutub al-'Ilmiyya.

BAššĀR B. Burd, A. M. (1981). Diَwān ديوان (Ed. M. B. al-D. al- 'Alawī). Beirut: Dār al-Taqāfa.

BayHaqī, A. B. al- (2009). Al-Da rwät al-kabìr الدعوات الكبير (Vol. 1) (Ed. B. b. 'A. A. al-Badr). Kuwait: Girās.

Bosworth, C. E. y Kaegi, W. E. (2002). Yarmūk. En P. Bearman, Th. Bianquis, C. E. Bosworth, E. van Donzel y W. P. Heinrichs (Eds.), The Encyclopaedia of Islam (2 ${ }^{\mathrm{a}}$ ed.) (Vol. 11, pp. 290-292). Leiden: E. J. Brill. https://doi.org/10.1163/1573-3912_islam_ COM 1359

BuHl, F. y Jomier, J. (1991). Mahmal. En P. Bearman, Th. Bianquis, C. E. Bosworth, E. van Donzel y W. P. Heinrichs (Eds.), The Encyclopaedia of Islam (2 ${ }^{\mathrm{a}}$ ed.) (Vol. 6, pp. 44-46). Leiden: E. J. Brill. https://doi.org/10.1163/1573-3912_islam_SIM_4789

DAнABī, Š. al-D. al- (1996). Siyar a lām al-nubalāt' سير أعلام النبلاء (Vol. 13) (Ed. 'A. Abū Zayd). Beirut: Mu' assasat al-Risāla.

Gabrieli, F. (1986). Adab. En P. Bearman, Th. Bianquis, C. E. Bosworth, E. van Donzel y W. P. Heinrichs (Eds.), The Encyclopaedia of Islam (2 ${ }^{\text {a }}$ ed.) (Vol. 1, pp. 175-176). Leiden: E. J. Brill. https:// doi.org/10.1163/1573-3912_islam_SIM_0293

Granja, F. de la (1970). Cuentos árabes en la "Floresta Española" de Melchor de Santa Cruz. Al-Andalus, 35(2), 381-400.

Halabī, N. al-D. al- (2006). Insān al-'uyūn fì Sìrat alAmin al-Ma'mūn, al-ma'rūfa bi l-Sìra al-ḅalabiyya إنسان العيون في سيرة الأمين المأمون المعروفة بالسيرة الحلبية (Vol. 3). Beirut: Dār al-Kutub al-'Ilmiyya. 
Ibn 'Abd Rabbini, A. (1949-1965). Kitābal- 'Iqd al-farid كتاب العقد الفريد (Vol. 6) (Eds. A. Amīn, A. al-Zayn e I. al-Abyārī). El Cairo: Laŷnat al-Ta'lif wa-l-Tarŷama wa-l-Našr.

IвN Aві̄ 'Awn, I. b. M. (1996). Kitāb al-aŷwiba al-muskita كتاب الأجوبة المسكتة (Ed. M. Ahmad Yūsuf). El Cairo: 'Ayn li 1-Dirāsāt wa-l-Buhūu al-Insāniyya wa-l-Iŷtimā iyya.

IBN AL-A Tīir, I. al-D. (1994). Usd al-gāba fì ma rifat as-sahāāba أسد الغابة في معرفة الصحابة (Vols. 2 y 3) (Eds. 'A. M. Mu'awwad y 'Ā. A. 'Abd al-Mawŷūd). Beirut: Dār al-Kutub al- Ilmiyya.

IBN 'Āṣı, A. B. (1987). Hadā' iq al-azāhir حدائق الأزاهر (Ed. 'A. 'Abd al-Raḥmān). Beirut: Dār al-Masīra.

IBN 'Āṣim, A. B. (2019). El libro de los huertos en flor (Hadā' iq alazāhir). Cuentos, refranes y anécdotas de la Granada nazarí (Trad. Desirée López Bernal). Granada: Editorial Universidad de Granada.

IBN Habīb, M. (199?). Kitāb al-Mubabbar كتاب المحبّر (Ed. I. Lichtenstädter). Beirut: Manšūrāt Dār al-Āfāq al-Ŷadīda.

Ibn Hamdūn, M. (1996). Al-Tadkira al-ḥamdūniyya التذكرة الحمدونية (Vol. 7) (Eds. I. 'Abbās y B. 'Abbās). Beirut: Dār Ṣādir.

IBN HAŶAR AL-'AsQALĀNİ, Š. al-D. (1995). Al-Isāaba fì tamyīz al-saḅāba الإصابة في تمييز الصحابة (Vol. 3) (Eds. 'Ā. A. 'Abd al-Mawŷūd y 'A. M. Mu'awwad). Beirut: Dār al-Kutub al-'Ilmiyya.

Ibn Manzūr, M. (1981). Lisān al- arab لسان العرب (Ed. 'A. A. 'Alī 1-Kabīr et al.). s. l.: s. e.

Ibn Qutayba, 'A. A. (1963). 'Uyūn al-ajbār عيون الأخبار (T. 4) (Ed. M. 'A. al-Q. Hātim). El Cairo: Wizārat al-Taqāfa.

IBn QuTAYBA, 'A. A. (1981). Al-Ma ārif المعارف (Ed. T. 'Ukāša). Beirut: Dār al-Ma'ārif.

JAṬīB AL-BAGDĀDī, A. B. A. al- (2000). Al-Bujalāà البخلاء (Ed. B. 'A. alW. al-Ŷābī). Beirut: Dār Ibn Hazm.

López Bernal, D. (2018). El texto sagrado al servicio de la risa en la literatura de $a d a b$. Apuntes a partir de los Hadá'iq al-azāhir de Ibn 'Āṣim (finales s. XIV). En S. Cohen (Ed.), Escritos y humanismo. Textos sagrados y sus influencias en literatura, cultura e historia (pp. 65-77). Granada: Editorial Universidad de Granada.

Malti-Douglas, F. (1997). Playing with the sacred: Religious intertext in Adab discourse. En A. Afsaruddin y A. H. Mathias Zahniser (Eds.), Humanism, culture and language in the Near East. 
Studies in honor of Georg Krotkoff (pp. 51-59). Winona Lake, IN: Eisenbrauns.

Marzolph, U. (2000). The Qoran and jocular literature. Arabica, 47(3), 478-487. https://doi.org/10.1163/157005800774230308

MAYdāNī, A. al- (1972). Maŷma al-amtāl مجمع الأمثال (T. 2) (Ed. M.

M. al-D. 'Abd al-Hamīd). El Cairo: Dār al-Fikr.

MusLim B. AL-HAŶYŶĀŶ (1427/2006). Saḅ̂h Muslim صحيح مسلم (Vol. 2)

(Ed. A. Q. N. M. al-Fāriyābī). Riad: Dār Tayyiba li l-Našr wa1-Tawzī'.

NisĀ' İ, A. al- (2001). Al-Sunan al-Kubrà السنن الكبرى (Vol. 9) (Ed. H. 'A. al-M. Šalabī). Beirut: Mu' assasat al-Risāla.

NuWAYRİ, Š. al-D. A. al- (2004). Nihāyat al-arab fī funūn al-adab نهاية الأرب في فنون الأدب (Vol. 3) (Ed. H. Nūr al-Dīn) Beirut: Dār al-Kutub al-'Ilmiyya.

PeLlat, Ch. (1976). Études sur l'histoire socio-culturelle de l'Islam (VII'$X V^{e}$ siècle). Londres: Variorum Reprints.

RĀGIB AL-Ișfahānī, A. Q. al-H. al- (2009). Muḅādarāt

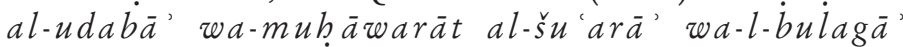
محاضر ات الأدباء ومحاور ات الثعر اء و البلغاء (Vol. 3) (Ed. S. al-Ŷubaylī). Beirut: Dār al-Kutub al-'Ilmiyya.

ȘAfADī, J. b. A. al- (1911). Nakt al-himyān fī nukat al-'umyān نكت الهميان في نكت العميان (Ed. A. Zakī). El Cairo: al-Maṭa'a alŶāmaliyya bi Miṣr.

ṢAfADİ, J. b. A. al- (1988). Al-Šu'ūurbil-'ūr الثعور بالعور (Ed. 'A. al-R. Husayn). Amán: Dār 'Ammār.

SuYūṬī, A. l-F. 'A. al-R. al- (1998). Ham 'al-hawāmi fī šarb ŶYam 'al-

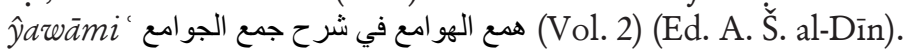
Beirut: Dār al-Kutub al-'Ilmiyya.

TAMER, G. (Ed.) (2009). Humour in der arabischen Kultur/Humour in Arabic culture. Berlín: De Gruyter. https://doi.org/10.1515/ 9783110211061

Tirmidī, A. 'I. M. al- (1996). Ŷāmi' al-Șahīḥ (Vol. 5) (Ed. B. 'A. Ma rūf). Beirut: Dār al-Garb al-Islāmī.

Watт, W. M. (1986). al-Hudaybiya. En P. Bearman, Th. Bianquis, C. E. Bosworth, E. van Donzel y W. P. Heinrichs (Eds.), The Encyclopaedia of Islam (2 ${ }^{\text {a }}$ ed.) (Vol. 3, p. 539). Leiden: E. J. Brill. https://doi.org/10.1163/1573-3912_islam_SIM_2922

Ŷ̀̄Ḥı, 'A. b. B. al- (1984). Libro de los avaros (Trad. S. Fanjul). Madrid: Editora Nacional. 
ŶĀḤIZ, 'A. b. B. al- (1990). Kitāb al-burșān wa-l- 'urȳān wa-l- 'umyān wal-ḥūtān كتاب البرصنان و العرجان و العميان والحو لان (Ed. 'A. al-S. M. Hārūn). Beirut: Dār al-Ŷ̄il.

Ŷ̀̄HIIZ, 'A. b. B. al- (s. a.). Kitāb al-bujalā’' كتاب البخلاء (Ed. Ṭ. al-Hâŷyirī). El Cairo: Dār al-Ma'ārif.

YĀQūt AL-Hạamawi [al-Rūmī], A. 'A. A. (1977). Mu ŷam al-buldān (Vol. 5). Beirut: Dār Șādir.

Yūsī, A. 'A. al-H. al- (1981). Zahr al-akam fì l-amtāal wa-l-hikam زهر الأكم في الأمثال والحكم (Vol. 1) (Eds. M. Haŷŷ̄i y M. al-Ajḍar). Casablanca: D̄ār al-Taqāäa.

ZABīdì, M. M. al- (1974). Tāŷy al-'arūs min ŷawāhir al-qāmūs تاج العروس من جواهر القاموس (Vol. 13) (Ed. H. Naș̣̄ār). Kuwait: Maṭa' at Hukūmat al-Kuwayt.

ZAMAjŠARİ, A. Q. M. al- (1987). Al-Mustaqșà fì amtāal al-'arab المستقصى في أمثال العرب (Vol. 1). Beirut: Dār al-Kutub al- 'Ilmiyya.

ZAMAJŠARİ, A. Q. M. al- (2006). Rabī al-abrār wa-nușūss al-ajbār ربيع الأبرار ونصوص الأخبار (T. 1) (Ed. T. F. al-Sayyid). Beirut: Dār al-Kutub al-'Ilmiyya.

Desirée López Bernal es doctora en estudios árabes e islámicos por la Universidad de Granada y profesora ayudante doctora en el Departamento de Estudios Semíticos de dicha institución. Su ámbito de investigación es la literatura árabe clásica oriental y andalusí, especialmente la prosa de humor y de $a d a b$. También la transmisión de dicha literatura a las letras y al folclor universal. Ha publicado más de una decena de artículos en revistas científicas, especializadas en estudios árabes y medievales, tradición oral e hispanismo.

http://orcid.org/0000-0002-9756-9062

desiree@ugr.es 
